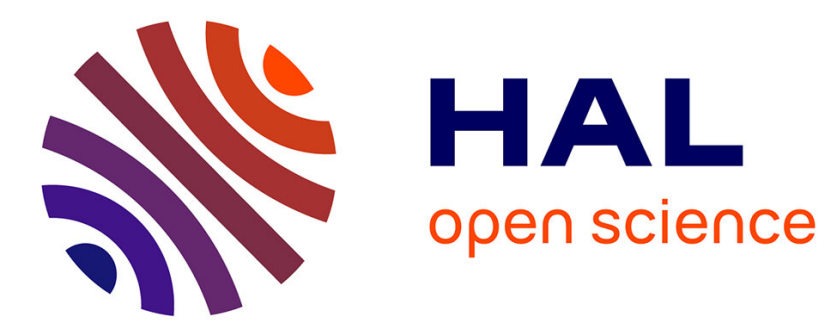

\title{
Microwave-Based Sensor Dedicated to the Characterization of Meat Freshness
}

Maréva Calvet-Chautard, Patricio Jaque Gonzalez, Thierry Véronèse, David Dubuc, Katia Grenier

\section{- To cite this version:}

Maréva Calvet-Chautard, Patricio Jaque Gonzalez, Thierry Véronèse, David Dubuc, Katia Grenier. Microwave-Based Sensor Dedicated to the Characterization of Meat Freshness. 2020 IEEE MTTS International Microwave Biomedical Conference (IMBioC), Dec 2020, Toulouse (virtual), France. pp.1-4, 10.1109/IMBIoC47321.2020.9385050 . hal-03253198

\section{HAL Id: hal-03253198 \\ https://hal.laas.fr/hal-03253198}

Submitted on 8 Jun 2021

HAL is a multi-disciplinary open access archive for the deposit and dissemination of scientific research documents, whether they are published or not. The documents may come from teaching and research institutions in France or abroad, or from public or private research centers.
L'archive ouverte pluridisciplinaire HAL, est destinée au dépôt et à la diffusion de documents scientifiques de niveau recherche, publiés ou non, émanant des établissements d'enseignement et de recherche français ou étrangers, des laboratoires publics ou privés. 


\section{Microwave-based sensor}

\section{dedicated to the characterization of meat freshness}

\author{
Maréva Calvet-Chautard \\ $L A A S$ \\ CNRS \\ Toulouse, France \\ mcalvetc@laas.fr \\ Katia Grenier \\ $L A A S$ \\ CNRS \\ Toulouse, France \\ grenier@laas.fr
}

\author{
Patricio Jaque Gonzalez \\ $L A A S$ \\ CNRS \\ Toulouse, France \\ pfjaqueg@laas.fr
}

\author{
Thierry Véronèse \\ Ovalie Innovaion \\ Auch, France \\ thierry.veronese@ovalie- \\ innovation.com
}

\author{
David Dubuc \\ $L A A S$ \\ CNRS \\ Toulouse, France \\ dubuc@laas.fr
}

\begin{abstract}
This paper presents a microwave sensor designed to dielectrically characterize tissues of animal origin (duck in our case) in the frequency range of 0.1 to $6 \mathrm{GHz}$ for meat freshness evaluation. This contact sensor is used as a transmit-and-receive sensor. Its validity is firstly verified with reference liquids. A dielectric characterization is then performed on a duck breast at different maturation days. In each case, repeatability of the measurements was checked. The obtained dielectric response of the duck breast changes over time. This result enables the future use of the sensor and the measurement technique in various applications and for the agroindustry notably for the monitoring of the meat freshness.
\end{abstract}

Keywords-meat freshness, sensor, coplanar waveguide, microwave, reflection coefficient, tissues.

\section{INTRODUCTION}

Microwave dielectric spectroscopy is a fast and noninvasive technique, which allows to characterize samples through their dielectric properties. This method is widely used in biology to characterize liquids or solid samples because of its high sensitivity to water. The use of non-ionizing electromagnetic waves such as microwaves to investigate biological samples presents a low health risk compared to Xrays. Associated to micrometric dimensions and microfluidics, the technique enables to study molecules, cells [1]-[3] and biological liquids, such as blood or eggs constituents for instance [4]. Broadband microwave characterizations are generally performed, whereas narrowband ones are prefered for sensitivity enhancement.

Moreover, microwave sensing and imaging may not only be of interest for biomedical applications, but also promise an impact in the field of agriculture [5] with food monitoring notably [6]-[7]. Food is indeed nothing but a biological tissue, which quality and freshness can be studied with microwave investigations. Some food, like fruit and fishes, have already been analyzed with various microwave sensing technique [8][10]. Microwave spectroscopy may represent an alternative to determine dielectric properties (dielectric constant and losses) of biological tissues ex-vivo and then in-vivo. Moreover, the expected devices offer the potential for low cost and portable systems, while providing real time quality information with a high sensitivity.

In the field of agriculture and food, studies have shown that meat quality depends on bacteria growth. Bacteria constitute indeed a major source of contamination in water and food supplies resulting in both food poisoning and diseases [11] Based on the degradation of food products due to the bacteria activity, one may expect that the dielectric properties of the sample under transformation and under test change as a function of time. The measurement of the dielectric signals related to the dielectric permittivity of the tissues under test may therefore represent a good indicator for the monitoring of food quality.

This paper presents thus a microwave sensor dedicated to the assessment of food quality. Its architecture is first introduced, followed by its microwave characterization in terms of reflection coefficient with different liquids, as well as penetration depth of the electromagnetic waves. Finally, dielectric measurements are performed on a duck breast sample for different days in order to evaluate the sensitivity of the sensor towards the meat freshness.

\section{DESCRIPTION OF THE SENSOR}

In order to allow the non-destructive dielectric characterization of tissues, a reflection microwave sensor based on a near-field capacitive topology is defined. A coplanar configuration is used with a circular patch as the centre 
conductor with the ground placed around. The circular patch presents a diameter of $8 \mathrm{~mm}$, whereas the slot is $2 \mathrm{~mm}$ wide. The thickness of the metallic layer is of $0.035 \mathrm{~mm}$. The ground plane area corresponds to 60 by $60 \mathrm{~mm}^{2}$, as shown in "Fig 1". This device is fabricated on a FR4 substrate exhibiting a thickness " $h$ " of $1.6 \mathrm{~mm}$ with a dielectric constant $\varepsilon_{\text {r }}$ equals to 4.4. The microwave sensor is fed on the back side by a microstrip line of $30 \mathrm{~mm}$ long and $2.5 \mathrm{~mm}$ wide. The back-side feeding part is connected to the radiative part through seven conductive vias. This contact sensor acts as a transmit-andreceive sensor, which radiates the electromagnetic field within the element of interest.
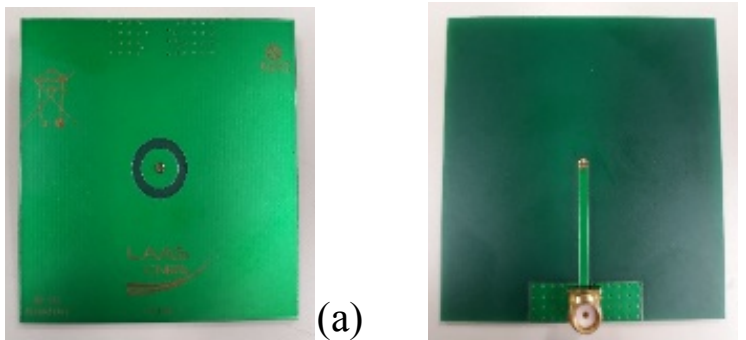

(b)

Fig 1. Photographies of the (a) front and (b) back sides of the microwave sensor

Next section is related to the microwave characterization of the sensor.

\section{MiCROWAVE CHARACTERIZATION OF THE SENSOR}

\section{A. Sensor evaluation while unloaded}

First, simulations are performed on the $\mathrm{HFSS}^{\odot}$ electromagnetic software in order to allow the study of the electromagnetic behavior of the sensor. In a first step, air is chosen as medium reference with a known permittivity. To compare simulation with reality we mesure the signal of the sensor in the air.

Dielectric measurements are performed with a Vector Network Analyser (VNA) from Copper Mountain Technologies that generates electromagnetic waves between 0.1 and $6 \mathrm{GHz}$. A SMA connector permits to connect the sensor to the VNA with a cable. Preliminary studies have demonstrated the importance of the contact between the sample and the sensor for good repeatability of the results. Consequently, a weight of $250 \mathrm{~g}$ behind the sensor is added during measurements to assure a precise and homogeneous pressure on the meat surface. After a traditional SOLT calibration step, the S11 parameter of the sensor is measured with different configuration, air and then in contact with meat.

"Fig.2" presents the simulated and measured magnitude of the reflection coefficient of the sensor in the air. Both curves present a similar trend with however some differences. These are due to the presence of the vias and mainly the connector, which are not included in the simulation.

To allow the measurement of biological tissues, the next interesting characteristic of the sensor consists in the penetration depth of the electromagnetic waves within the tissue.

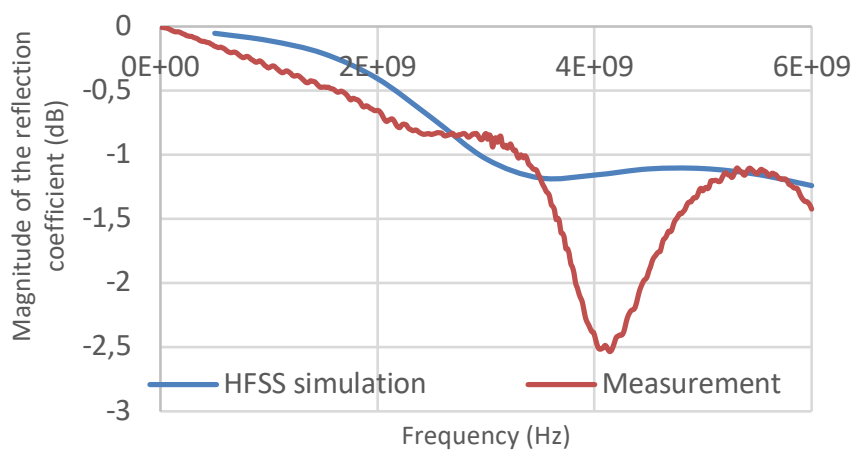

Fig 2. Simulated ant measured magnitude of the reflection coefficient in the air

\section{B. Penetration depth of the electromagnetic waves}

To dielectrically characterize meat samples with this nearfield sensor, we have chosen to place the sensor in direct contact with the meat. To determine the penetration depth of the electromagnetic waves in the sample, specific experiments are conducted. They consist in placing in a flask filled with deionized water in front of the sensor while changing the distance between this flask and the sensor. The flask contains a water volume of $15 \mathrm{~mL}$. The measured magnitude of the S11 parameter at $4 \mathrm{GHz}$ is indicated in the "Fig. 3", depending on the flask-sensor distance. A criterion to define that the electromagnetic field interaction with the sample is negligible consists in getting a magnitude of $-0.1 \mathrm{~dB}$. Therefore, the penetration depth of this sensor is located at $15 \mathrm{~mm}$. The

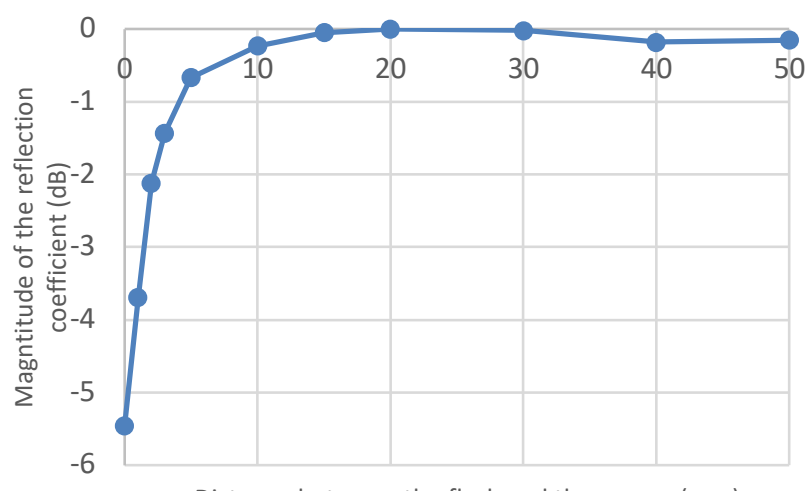

Fig 3. Magnitude of the reflection coefficient for different distances between the water flask and the sensor at $4 \mathrm{GHz}$.

samples to analyze with this sensor must consequently present a thickness of at least $15 \mathrm{~mm}$ to obtain a dielectric response.

\section{Evaluation of reference liquids}

Before study biological tissues, we investigate several reference liquids in order to evaluate if this electromagnetic sensor is able to differentiate distinct materials. Water and oil, which exhibit very different permittivity values (real and 
imaginary parts) are chosen. Water presents a much higher relative permittivity ( 75 and 15 at $4 \mathrm{GHz}$ ) compare to oil $(2,5$ and 2 at 4GHz). These two liquids present very apart dielectric properties, which frames those of duck breast meat, composed of muscle (with high water content) and lipids.

Measurements are performed 5 times for each liquid in order to also study the repeatability. Corresponding measurements are presented in "Fig. 4". For frequencies higher than $1 \mathrm{GHz}$ the sensor gives a different dielectric response for both liquids. The disparity can reach a $4 \mathrm{~dB}$ variation in magnitude and $50^{\circ}$ for the phase. An excellent repeatability of the measurements is also obtained (with a standard deviation of $0,05 \mathrm{~dB}$ for the magnitude of water and $1,2^{\circ}$ for its phase), which demonstrates the appropriate sensitivity of the characterization technique for the targeted application.

Next section is dedicated to the evaluation of a breast duck sample and its monitoring during several days.
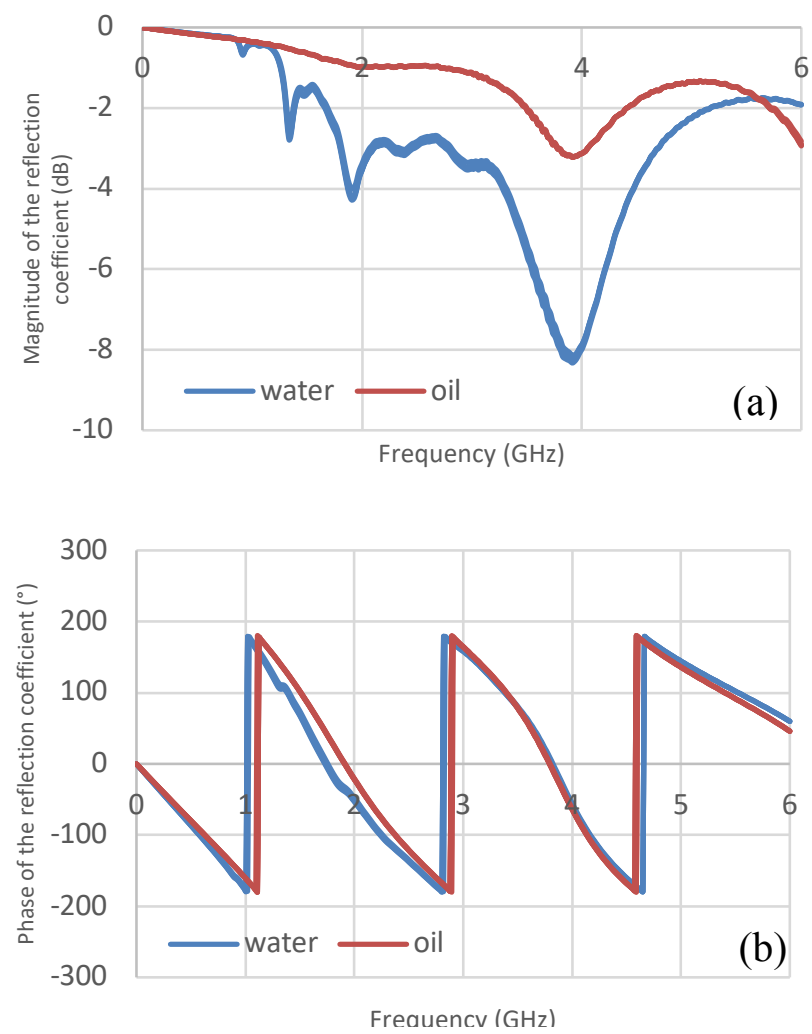

Fig 4.Magnitude (a) and phase (b) of the reflection coefficient for water and oil

\section{STUDY OF A BIOLOGICAL TISSUES}

In this section, a duck breast is studied at different maturation day in order to follow the bacteria contamination, in relation with the quality of food. Measurements are performed ex-vivo in the frequency range of 0.5 to $6 \mathrm{GHz}$. The meat samples are excised from a duck, which is slaughtered the same day as the first microwave measurements. The samples are cut in order to cover the entire surface of the sensor. Therefore the entire organ is removed from the duck. In this case, the thickness of the sample is higher than $15 \mathrm{~mm}$ and large enough to cover the entire sensor $\left(60 \times 60 \mathrm{~mm}^{2}\right)$. Measurements are realized at ambient temperature.

Five measurements are done at the same location on the sample at different time of maturation, day $0,5,7,14$ and 21 . To do so, the meat sample is removed from the sensor and

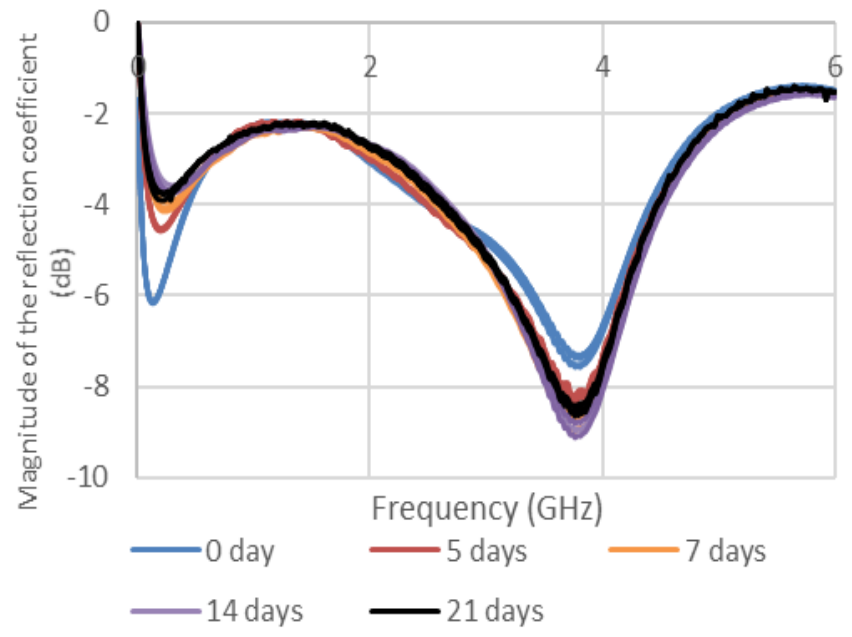

Fig 5. Magnitude of the reflection coefficient for different day of maturation

placed again afterwards. Between measurements at different days, the samples are kept in a fridge at $4{ }^{\circ} \mathrm{C}$. Before each RF characterization, the samples are taken out of the fridge and maintain at room temperature $\left(22^{\circ} \mathrm{C}\right)$ until they exhibit the same temperature as for the precedent measurements to avoid any temperature dependency variation and to focalize the results only on meat transformation. "Fig. 5." presents the results of this study. Once again, for each day, the RF measurements are performed 5 times, as illustrated in "Fig. 5". For two particular frequencies, the dielectric response varies during the maturation. At $0.24 \mathrm{GHz}$, the magnitude is increasing with the number of days, whereas an opposite behaviour is obtained at $3.76 \mathrm{GHz}$. On this graph, one may also observe also the good repeatability of the measurements.

To analyze more precisely this evolution, the phase and the magnitude of the $\mathrm{S} 11$ parameter at $0.24 \mathrm{GHz}$ are plotted on the same graph, as shown in "Fig. 6".

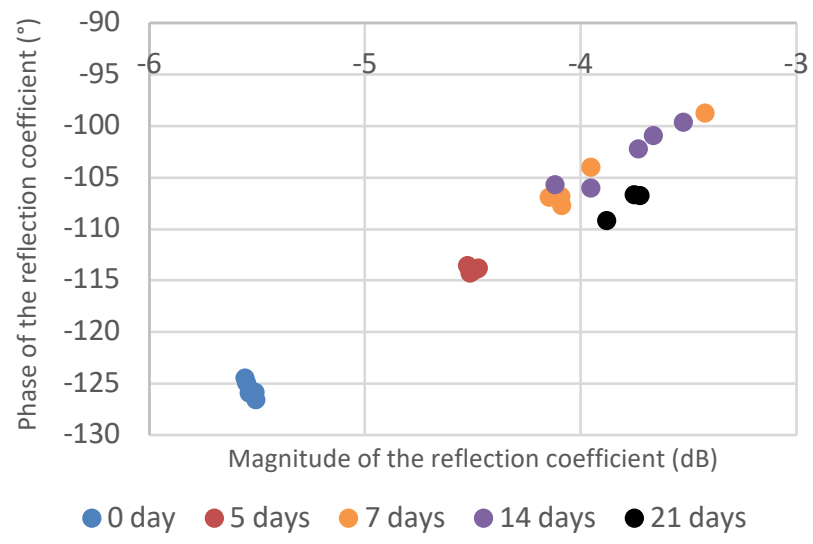

Fig 6. Magnitude and phase of the reflection coefficient at $0.24 \mathrm{GHz}$ 
The major modification on the S11 parameter is obtained during the first days of the experiment, leading to a variation of $1 \mathrm{~dB}$ and $12^{\circ}$ from day 0 to day 5 and $2 \mathrm{~dB}$ and $20^{\circ}$ from day 0 to day 7 . The dielectric response seems to saturate after one week. This modification is mainly attributed to the presence and the proliferation of bacteria, as well as the transformation of the meat. These results validate the possible use of the proposed microwave sensor for the analysis of the meat quality.

\section{CONCLUSION}

A microwave sensor devoted to the dielectric characterization performed in reflection of biological tissues is introduced. This sensor has been evaluated with different samples, reference liquids and biological tissues with the targeted application of monitoring the freshness of meat. The near-field sensor presents a penetration depth of $15 \mathrm{~mm}$ and is capable to differentiate oil from water in terms of magnitude and phase. Duck breast tissues have also been monitored for several days, exhibiting a modification of the dielectric responses versus time. This variation may be attributed to the proliferation of bacteria and the transformation of the meat. Therefore, this sensor, allied with a low-cost technology and a portable and affordable VNA enables the use of the technique for the evaluation of meat freshness and may find further applications in the agroindustry field.

\section{REFERENCES}

[1] K. Grenier et al., "Integrated broadband microwave and microfluidic sensor dedicated to bioengineering," IEEE Trans. Microw. Theory Tech., vol. 57, no. 12, pp. 3246-3253, 2009.

[2] A. Zedek, D. Dubuc, and K. Grenier, "Microwave permittivity extraction of individual biological cells submitted to different stimuli," presented at the Microwave Symposium (IMS), 2017 IEEE MTT-S International, 2017, pp. 865-868. [

[3] Y. Ning et al., "Broadband electrical detection of individual biological cells," IEEE Trans. Microw. Theory Tech., vol. 62, no. 9, pp. 19051911, 2014.

[4] P Jaque Gonzalez, D. Dubuc, Katia Grenier, T. Veronese, 2019 49th European Microwave Conference (EuMC), Oct 2019, Paris, France. pp.204-207.

[5] G. Brodie, M.V. Jacob, P. Farrell, " Microwave and radio-frequency technologies in agriculture", Berlin ,2015,355p.

[6] S. Clerjon, J.L. Damez, "Microwave sensing for an objective evaluation of meat ageing", Journal of Food Engineering, 94 (3-4) (2009), pp. 379389.

[7] Damez, J. L. and Clerjon, S. 2008. Meat quality assessment using biophysical methods related to meat structure. Meat Science., 80(1): 132-149.

[8] S. O. Nelson, W. Guo, S. Trabelsi, and S. J. Kays, "Sensing quality of watermelons through dielectric permittivity," in Antennas and Propagation Society International Symposium, 2007 IEEE, 2007, pp. 285-288.

[9] S. O. Nelson, W. Guo, and S. Trabelsi, "Study of fruit permittivity measurements for quality detection," in Instrumentation and Measurement Technology Conference Proceedings, 2008. IMTC 2008. IEEE, 2008, pp. 1009-1011.

[10] S. Redzwan, M. D. Perez, J. Velander, and R. Augustine, "Study of Maturity Fruit Assessment using Permittivity and Microwave Reflectivity Measurements for Quality Classification," in 2018 IEEE Conference on Antenna Measurements \& Applications (CAMA), 2018, pp. 1-3.

[11] CDC data at http://www.cdc.gov/mmwr/PDF/ss/ss4901.pdf. 